Бюл. Бот. сада Сарат. гос. ун-та. 2017. Т. 15, вып. 1. С. $60-68$

УДК 581.1

\title{
ВЛИЯНИЕ ПЕРХЛОРАТОВ ХАЛЬКОГЕН(ТИО)ПИРИЛИЯ НА МОРФОГЕНЕЗ И ПИГМЕНТНЫЙ СОСТАВ ПЕРВОГО ЛИСТА ПРОРОСТКОВ ПШЕНИЦЫ
}

\author{
В. В. Коробко, Н. В. Пчелинцева, Е. А. Самсонова, \\ Аль Саммарраи Анес Исмаил Салех
}

\author{
Саратовский нацииоальный исследовательский государственный \\ университет им. Н. Г. Чернышевского \\ Россия, 410012, Саратов, Астраханская, 83 \\ E-mail:v.v.korobko@mail.ru
}

Поступила в редакцию 30.01.2017 г.

\begin{abstract}
Влияние перхлоратов халькоген(тио)пирилия на морфогенез и пигментный состав первого листа проростков пшеницы. - Коробко В. В., Пчелинцева Н. В., Самсонова Е. А., Аль Саммарраи Анес Исмаил Салех. - Проведено биологическое тестирование синтетических гетероциклических соединений - перхлоратов(тио)пирилия, отличающихся природой гетероатома $(\mathrm{O}, \mathrm{S})$ и характером заместителей $\left(\mathrm{CH}_{3}, \mathrm{Cl}, \mathrm{OCH}_{3}, \mathrm{C}_{6} \mathrm{H}_{5}\right)$ в катионе халькогенопирилия. Концентрацию веществ устанавливали по молекулярному весу, в трех характерных для физиологически активных веществ действующих дозах: $10^{-6} \mathrm{M}, 10^{-9} \mathrm{M}, 10^{-12} \mathrm{M}$. Объектом исследования служили проростки яровой мягкой пшеницы Triticum aestivum L. сорта Саратовская 36.

Для изучения влияния гетероциклических соединений на рост и развитие первого листа использовали следующие параметры: длину пластинки и влагалища первого листа (на основании которых рассчитывали абсолютную скорость роста). Все гетероциклические соединения оказали стимулирующее действие на рост влагалища первого листа. Положительное воздействие испытуемых соединений на рост листовой пластинки в длину менее выражено. В ряде случаев наблюдалось подавление роста листовой пластинки. Несмотря на различное влияние гетероциклических соединений на рост влагалища и пластинки, существенных различий по длине первого листа опытных и контрольных растений не наблюдается. Анализ кривых скорости роста показал, что присутствие в соединениях атома кислорода в качестве гетероатома приводит к сокращению периода роста листа в длину. Установлено влияние испытуемых веществ на количественный состав фотосинтезирующих пигментов в пластинке первого листа. Действие испытуемых растворов (за некоторым исключением) приводит к повышению соотношения хлорофил-
\end{abstract}

(C) Коробко В. В., Пчелинцева Н. В., Самсонова Е. А., Аль Саммарраи Анес Исмаил Салех, 2017 


\section{ВЛИЯНИЕ ПЕРХЛОРАТОВ ХАЛЬКОГЕН(ТИО)ПИРИЛИЯ}

лов $a / b$. Определение количественного содержания хлорофилла $a$ и $b$ в листовых пластинках позволяет предположить, что ингибирующее действие соединений на хлорофилл $b$ и стимулирующее на хлорофилл $a$ в большей степени связано с наличием атома кислорода в качестве гетероатома и атома хлора в качестве заместителя в катионе халькогенопирилия.

Анализ полученных данных позволяет сделать вывод, что испытуемые синтетические гетероциклические соединения, перхлораты (тио)пирилия, обладают росторегулирующей активностью. Проведенное лабораторное исследование может служить основой для дальнейших исследований росторегуляторных свойств этих соединений.

Ключевые слова: гетероциклические соединения, регуляторы роста, биотестирование, рост и развитие растений.

Effect of perchlorates halkogen(thio)pyrilium on morphogenesis and pigment composition of the first leaves of wheat seedlings. - Korobko V. V., Pchelintseva N. V., Samsonova E. A., Al Sammarrai Anes Ismail Saleh. A biological testing synthetic heterocyclic compounds - perchlorates (thio)pyrylium differing nature of the heteroatom $(\mathrm{O}, \mathrm{S})$ and alternate character $\left(\mathrm{CH}_{3}, \mathrm{Cl}, \mathrm{OCH}_{3}, \mathrm{C}_{6} \mathrm{H}_{5}\right)$ in the cation halkogenopyrylium. The concentration of substances established by the molecular weight, in the three specific to physiologically active substances acting doses: $10^{-6} \mathrm{M}, 10^{-9} \mathrm{M}, 10^{-12} \mathrm{M}$. The objects of the study were the seedlings of spring wheat Triticum aestivum $L$.

To study the effect of heterocyclic compounds on the growth and development of the first leaf using the following parameters: the length of the lamina and sheath, which is calculated on the basis of the absolute growth rate. All of heterocyclic compounds have a stimulating effect on the growth of the first leaf sheath. Positive effects of test compounds on the growth of the leaf lamina is less pronounced. In a number of cases was observed inhibition of growth of the leaf lamina. Despite the different effects of heterocyclic compounds on growth of parts of the first leaf, significant differences in the length of the first sheet of the experimental and control plants was observed. Analysis of growth rate showed that the presence of compounds of the oxygen atom as the heteroatom, resulting reduction of the growth period of leaf lamina. The effect of the test substances on the quantitative composition of photosynthetic pigments in the lamina of the first leaf. The action of the test solutions (with some exceptions) increases the ratio of chlorophyll $a / b$. Determination of quantitative content of chlorophyll $a$ and $b$ in the lamina suggests that the inhibitory effect of the compounds on the and chlorophyll $b$ and the stimulatory effect on chlorophyll $a$ is associated with the presence of $\mathrm{O}$ as a hetero atom and $\mathrm{Cl}$ as a substituent.

Analysis of the results leads to the conclusion that the tested synthetic heterocyclic compounds - perchlorates (thio)pyrylium have regulatory activity. Laboratory research can serve as a basis for further studies the physiological properties of these compounds.

Key words: heterocyclic compounds, growth regulators, biological testing, plant growth and development. 
В. В. Коробко, Н. В. Пчелинцева, Е. А. Самсонова и др.

DOI: 10.18500/1682-1637-2017-15-1-60-68

По разнообразию гетероциклические соединения занимают одно из первых мест среди органических соединений и благодаря широкому спектру биологических свойств интерес к синтезу и изучению активности препаратов очень высок. В основном биологические методы определения физиологической активности веществ основаны на учете ростовых реакций растений (Жигачева, Спивак, 2010). Одним из наиболее важных показателей продуктивности является степень развития фотосинтетического аппарата, дающая представление о потенциальных возможностях растительного организма (Тарчевский, Андрианова, 1980).

Целью данного исследования является изучение действия на растительный тест-объект гетероциклических синтетических соединений, а именно солей халькогенопирилия, отличающихся природой гетероатома и характером заместителей в катионе халькогенопирилия.

\section{Материалы и методы}

Исследования проводились в 2016 г. на кафедре микробиологии и физиологии растений Саратовского национального исследовательского государственного университета.

Биотестированию подвергнуты гетероциклические соединения ряда солей халькогенопирилия (рис. 1) - перхлораты 3,5-диметил-4-(4метоксифенил)-2,6-дифенилтиопирилия (МФТП), 3,5-диметил-4-(4метоксифенил)-2,6-дифенилпирилия (МФП) и 2,4,6-трифенил-3хлортиопирилия (ХTП), отличающиеся природой гетероатома $(\mathrm{O}, \mathrm{S})$ и характером заместителей $\left(\mathrm{CH}_{3}, \mathrm{Cl}, \mathrm{OCH}_{3}, \mathrm{C}_{6} \mathrm{H}_{5}\right)$ в катионе халькогенопирилия. Из исследуемых перхлоратов халькогенопирилия МФП известен, МФТП впервые получен при окислении тиопирана (Пчелинцева и др., 1979, 1981), ХТП в результате гетероциклизации 1,3,5трифенил-2,4-дихлор-2-пентен-1,5-диона в присутствии сероводорода (Пчелинцева, Харченко,1996) на кафедре органической и биоорганической химии Института химии Саратовского национального исследовательского государственного университета.

Синтезированные перхлораты (тио)пирилия представляют собой окрашенные в желтый цвет кристаллические вещества, с высокими температурами плавления, хорошо растворимые в этаноле, диметил- 


\section{ВЛИЯНИЕ ПЕРХЛОРАТОВ ХАЛЬКОГЕН(ТИО)ПИРИЛИЯ}

формамиде (ДМФА), хлороформе, плохо растворимые в воде. Концентрацию веществ устанавливали по молекулярному весу, в трех характерных для физиологически активных веществ действующих дозах: $10^{-6} \mathrm{M}, 10^{-9} \mathrm{M}, 10^{-12} \mathrm{M}$.

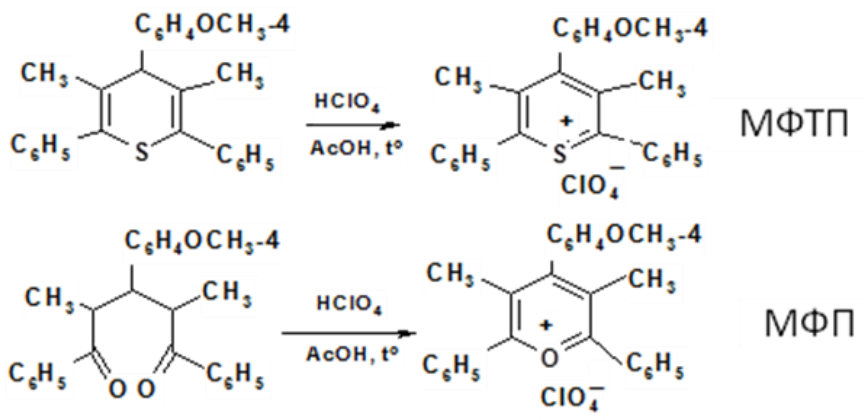<smiles>CCCCCCCCCCCCC(=O)C(Cl)=C(CC)C(=O)O</smiles>

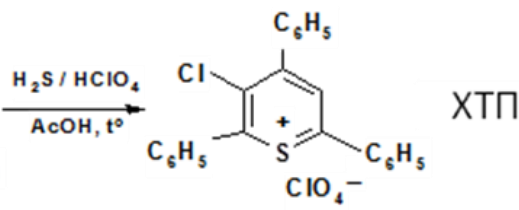

Рис.1. Получение полизамещенных перхлоратов (тио)пирилия:

МФТП - перхлорат 3,5-диметил-4-(4-метоксифенил)-2,6-дифенилтиопирилия; МФП - перхлорат 3,5-диметил-4-(4-метоксифенил)-2,6-дифенилпирилия; ХТП - перхлорат 2,4,6-трифенил-3-хлортиопирилия

Объектом исследования служили проростки яровой мягкой пшеницы Triticum aestivum L. сорта Саратовская 36. Культивирование осуществлялось в климатостате при температуре $+18{ }^{\circ} \mathrm{C}$. Морфометрическое изучение объектов включало измерение длины пластинки и влагалища первого листа проростков на 6, 10, 13 и 16-е дни вегетации $(n=20)$. Абсолютную скорость роста рассчитывали по формуле $C=L_{2}-L_{1} / t_{2}-t_{1}$, где $L_{2}$ и $L_{1}-$ длина частей листа в моменты времени $t_{2}$ и $t_{1}$. Количественное содержание пигментов в пластинке первого листа определяли на двухнедельных проростках. Результаты исследований подвергались статистической обработке в табличном процессоре Excel пакета MS Offce 2010. 
В. В. Коробко, Н. В. Пчелинцева, Е. А. Самсонова и др.

\section{Результаты и их обсуждение}

Влияние гетероциклических соединений на рост и развитие надземной части проростка оценивали по длине первого листа, а также выраженности его частей - пластинки и влагалища. На основании анализа полученных данных установили, что испытуемые растворы оказывают различное влияние на рост пластинки и влагалища. При этом существенных различий по длине первого листа опытных и контрольных растений не наблюдается. Все испытуемые растворы оказали стимулирующее действие на рост влагалища первого листа. В большей степени стимулирующий эффект проявился при концентрации $10^{-9} \mathrm{M}$ ХТП и МФТП, при концентрации $10^{-6}$ М МФП. Положительное действие на удлинение листовой пластинки опытных растений менее выражено, чем на влагалище листа, а в ряде случаев наблюдалось подавление роста листовой пластинки. Наибольший подавляющий эффект ( $81 \%$ от контроля) отмечен при действии МФП в концентрации $10^{-6} \mathrm{M}$; при том, что этот раствор наиболее эффективно из всех воздействовал на длину листового влагалища.

Анализ кривых скорости роста листовых пластинок показал, что при действии МФТП на 6-й день вегетации существенных отличий в скорости роста листовых пластинок опытных и контрольных растений нет (рис. 2).

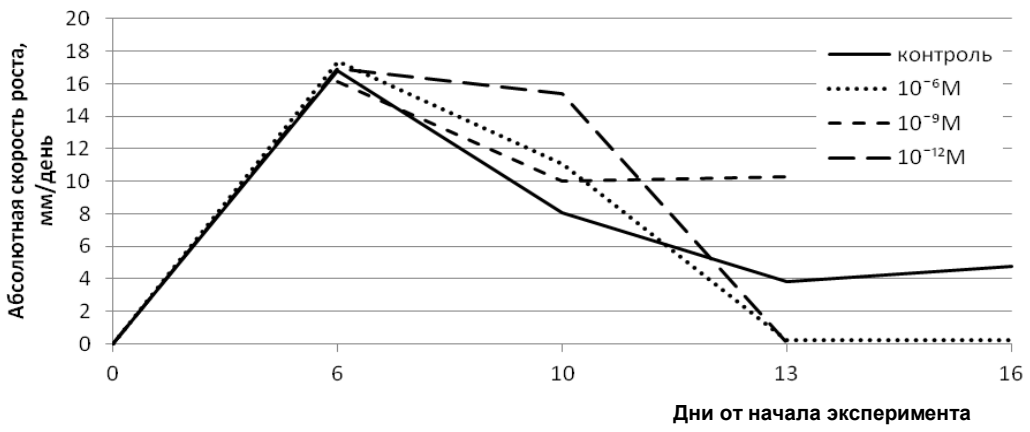

Рис. 2. Влияние перхлората 3,5-диметил-4-(4-метоксифенил)-2,6дифенилтиопирилия на рост пластинки первого листа проростков 


\section{ВЛИЯНИЕ ПЕРХЛОРАТОВ ХАЛЬКОГЕН(ТИО)ПИРИЛИЯ}

На 10-й день от начала эксперимента самая высокая скорость роста листовой пластинки отмечена при действии $10^{-12} \mathrm{M}$, она превышает контрольное значение в 1.9 раз. На 13-й день от начала эксперимента наблюдалось снижение скорости роста листовых пластинок проростков, культивированных при концентрациях $10^{-6} \mathrm{M}$ и $10^{-12} \mathrm{M}$, тогда как при концентрации $10^{-9} \mathrm{M}$ скорость роста превысила контрольное значение в 2.5 раза.

При действии МФП в концентрации $10^{-12} \mathrm{M}$ наблюдается превышение контрольных значений на $55 \%$ на 10-й день вегетации, на 13-й день скорость роста минимальна и составляет 33 \% от контроля (рис. 3). Растворы двух других концентраций приводят к повышению значений скорости роста относительно контроля на $67-68 \%$ на 10 день вегетации, а к 13 дню рост листовой пластинки уже закончен.

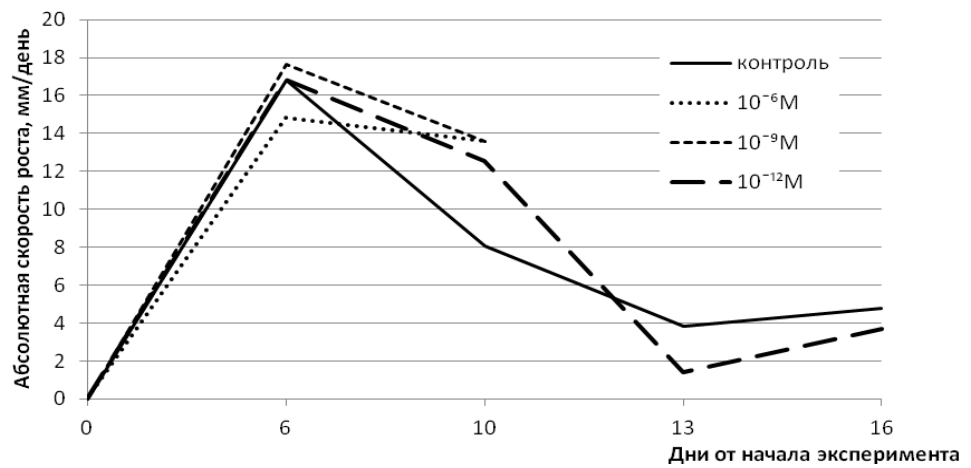

Рис. 3. Влияние перхлората 3,5-диметил-4-(4-метоксифенил)-2,6дифенилпирилия на рост пластинки первого листа проростков

Абсолютная скорость роста листовой пластинки проростков, культивированных на растворах ХТП к 10-му дню вегетации превышает контроль в 1,6 раза при концентрациях $10^{-9} \mathrm{M}$ и $10^{-12} \mathrm{M}$, в 2 раза при $10^{-6} \mathrm{M}$ (рис. 4). В течение следующих 6 дней скорость роста при действии концентрации $10^{-9} \mathrm{M}$ снижается, составляя $6 \%$ от контроля на 13-й день вегетации. Листовая пластинка проростков при других 
В. В. Коробко, Н. В. Пчелинцева, Е. А. Самсонова и др.

концентрациях раствора ХТП достигает своей окончательной длины на 10-й день.

Информативным параметром, характеризующим развитие фотосинтетического аппарата растений, является пигментный состав (Тарчевский, Андрианова, 1980). В результате проведенного исследования установлено влияние испытуемых веществ на количественный и качественный состав фотосинтезирующих пигментов (таблица).

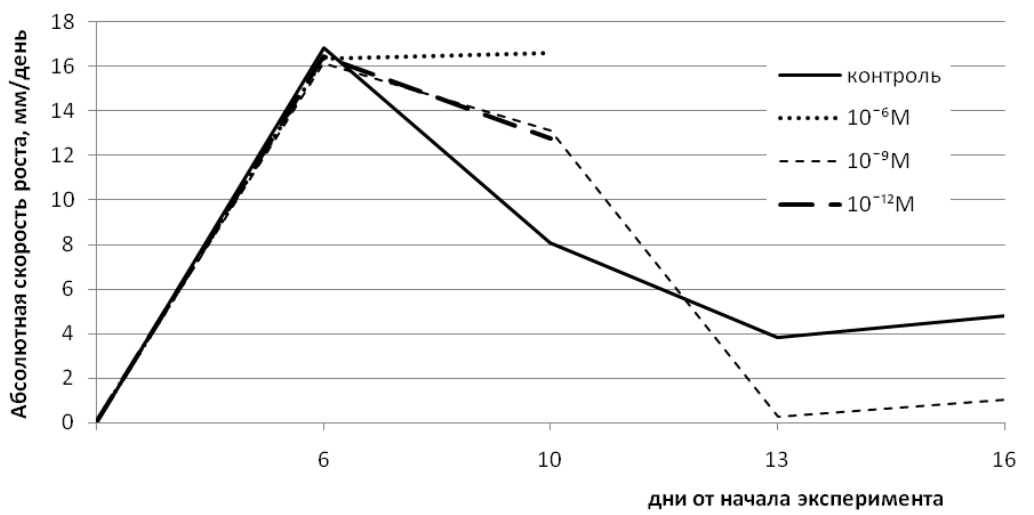

Рис. 4. Влияние перхлората 2,4,6-трифенил-3-хлортиопирилия на рост пластинки первого листа проростков

При культивировании проростков на испытуемых растворах наблюдается повышение соотношения количества хлорофилла $a$ к хлорофиллу $b$ относительно контрольных значений. Исключение составил вариант с использованием МФТП в концентрации $10^{-6} \mathrm{M}$ : соотношение зеленых пигментов пластинки первого листа опытных растений было ниже контрольных значений на $29 \%$.

Сравнение влияния МФП и ХТП на соотношение зеленых пигментов показало, что при концентрациях $10^{-6} \mathrm{M}$ и $10^{-9} \mathrm{M}$ наблюдается повышение значения $a / b$, причем в большей степени это проявляется для МФП. Дальнейшее снижение концентрации ХТП приводит к повышению величины соотношения $a / b$ (в 1.4 выше контроля); тогда как при действии МФП данный показатель снижается. 


\section{ВЛИЯНИЕ ПЕРХЛОРАТОВ ХАЛЬКОГЕН(ТИО)ПИРИЛИЯ}

Повышение содержания каротиноидов относительно контроля отмечено при действии МФП и ХТП в концентрациях $10^{-6} \mathrm{M}$ и $10^{-9} \mathrm{M}$, МФТП - в концентрации $10^{-12}$ М. Значительное ингибирующее действие проявилось при действии ХТП в концентрации $10^{-12} \mathrm{M}$ (77\% от контроля), менее выраженное - при культивировании на растворах МФП в концентрации $10^{-12} \mathrm{M}$ и МФТП в концентрации $10^{-9} \mathrm{M}$.

Количественное содержание пигментов в пластинке первого листа проростка, \% от контрольных значений

\begin{tabular}{|c|c|c|c|c|c|c|}
\hline \multirow{2}{*}{\multicolumn{2}{|c|}{$\begin{array}{l}\text { Испытуемое } \\
\text { соединение }\end{array}$}} & \multicolumn{2}{|c|}{ Хлорофилл } & \multirow{3}{*}{$\begin{array}{c}\text { Каратинои- } \\
\text { ды } \\
\\
99.2 \\
\end{array}$} & \multirow{3}{*}{$\begin{array}{c}\text { Суммарное } \\
\text { содержание } \\
\text { зеленых пиг- } \\
\text { ментов } \\
109.7 \\
\end{array}$} & \multirow{3}{*}{$\begin{array}{l}a / b \\
\\
70.8 \\
\end{array}$} \\
\hline & & \multirow{2}{*}{$\begin{array}{c}a \\
101.0 \\
\end{array}$} & \multirow{2}{*}{$\begin{array}{c}b \\
142.6 \\
\end{array}$} & & & \\
\hline \multirow[t]{3}{*}{ МФТП } & $10^{-6} \mathrm{M}$ & & & & & \\
\hline & $10^{-9} \mathrm{M}$ & 99.9 & 94.4 & 93.3 & 98.7 & 105.9 \\
\hline & $10^{-12} \mathrm{M}$ & 114.0 & 93.0 & 108.1 & 109.6 & 122.6 \\
\hline \multirow[t]{3}{*}{ МФП } & $10^{-6} \mathrm{M}$ & 111.8 & 91.0 & 111.0 & 107.5 & 122.9 \\
\hline & $10^{-9} \mathrm{M}$ & 111.4 & 86.0 & 106.4 & 106.1 & 129.5 \\
\hline & $10^{-12} \mathrm{M}$ & 90.1 & 75.3 & 92.3 & 87.0 & 119.6 \\
\hline \multirow[t]{3}{*}{ ХТП } & $10^{-6} \mathrm{M}$ & 112.5 & 98.3 & 116.2 & 109.5 & 114.4 \\
\hline & $10^{-9} \mathrm{M}$ & 111.0 & 94.9 & 115.3 & 107.6 & 116.9 \\
\hline & $10^{-12} \mathrm{M}$ & 71.6 & 49.6 & 76.8 & 66.9 & 144.3 \\
\hline
\end{tabular}

\section{Заключение}

Установлено, что присутствие в гетероциклическом соединении атома кислорода в качестве гетероатома приводит к ускорению развития листа: при концентрации раствора $10^{-6} \mathrm{M}$ к 10 -му дню вегетации рост листа в длину заканчивается.

Все испытанные субстраты в той или иной концентрации подавляют рост пластинки листа. Соединения с одинаковыми заместителями в катионе - МФП и МФТП - это действие проявляют при концентрации $10^{-6} \mathrm{M}$, причем МФП в большей степени, что, возможно, связано с наличием кислорода в качестве гетероатома. ХТП, характеризующийся одинаковым с МФТП гетероатомом, но в качестве заместителей имеющий атом хлора в гетероцикле, этот эффект демонстрирует при более слабых концентрациях. Все соединения оказывали стимулирующее действие на рост влагалища листа, при этом общая длина листа меняется несущественно относительно контроля. МФП, имеющий в 
В. В. Коробко, Н. В. Пчелинцева, Е. А. Самсонова и др.

качестве гетероатома О, оказал максимальный стимулирующий эффект на рост влагалища, максимальный подавляющий - на рост пластинки.

МФТП отличается от ХТП по характеру заместителей, а от МФП - по характеру гетероатома. Определение количественного содержания хлорофилла $a$ и $b$ в листовых пластинках позволяет предположить, что ингибирующее действие соединений на хлорофилл $b$ и стимулирующее на хлорофилл $a$ в большей степени связано с наличием О в качестве гетероатома (МФП) и $\mathrm{Cl}$ в качестве заместителя (ХТП). На содержание каротиноидов в пластинке первого листа проростка концентрированные растворы МФП и ХТП влияют положительно, а МФТП - отрицательно. В совокупности действие испытуемых растворов приводит к повышению соотношения хлорофиллов $a / b$, за исключением концентрированного раствора МФТП.

Таким образом, результаты проведенного биотестирования гетероциклических соединений, отличающихся природой гетероатома $(\mathrm{O}, \mathrm{S})$ и характером заместителей $\left(\mathrm{CH}_{3}, \mathrm{Cl}, \mathrm{OCH}_{3}, \mathrm{C}_{6} \mathrm{H}_{5}\right)$ в катионе халькогенопирилия, позволяют сделать вывод о возможности использования этих соединений в качестве регуляторов роста растений.

\section{Список литературы}

Жигачева В. И., Спивак В. А. Биотестирование гетероциклических синтетических соединений некоторыми растительными объектами // Бюл. Бот. сада Сарат. гос. ун-та. Саратов: Изд-во Сарат. ун-та, 2010. Вып. 9. С. 179 - 185.

Пчелинцева Н. В., Харченко В. Г., Кожевникова Н. И. Окислительное образование солей тиопирилия полизамещенными тиопиранами // Химия гетероцикл. соедин. 1979. № 4. С. $562-568$.

Пчелинцева Н. В., Харченко В. Г., Кожевникова Н. И., Куликова Л. К. Синтез, противораковая и антифаговая активность полизамещенных перхлоратов тиопирилия // Хим.-фарм. журн. 1981. № 4. С. $40-45$.

Пчелинцева Н. В., Харченко В. Г. Непредельные 1,5-дикетоны, их галогензамещенные - получение и использование в синтезе гетероциклов // Химия гетероцикл. соедин. 1996. № 10. С. $1299-1319$.

Тарчевский И. А., Андрианова Ю. Е. Содержание пигментов как показатель мощности развития фотосинтетического аппарата у пшеницы // Физиология растений. 1980. Т. 27, вып.2. С. $341-348$. 